\title{
Invasive clonal plant species have a greater root-foraging plasticity than non-invasive ones
}

\author{
Lidewij H. Keser • Wayne Dawson · Yao-Bin Song • \\ Fei-Hai Yu $\cdot$ Markus Fischer $\cdot$ Ming Dong $\cdot$ \\ Mark van Kleunen
}

\begin{abstract}
Clonality is frequently positively correlated with plant invasiveness, but which aspects of clonality make some clonal species more invasive than others is not known. Due to their spreading growth form, clonal plants are likely to experience spatial heterogeneity in nutrient availability. Plasticity in allocation of biomass to clonal growth organs and roots may allow these plants to forage for high-nutrient patches. We investigated whether this foraging response is stronger in species that have become invasive than in species that have not. We used six confamilial pairs of native European clonal plant species differing in invasion success in the USA. We grew all species in large pots under homogeneous or heterogeneous nutrient conditions in a greenhouse, and compared their nutrientforaging response and performance. Neither invasive nor
\end{abstract}

\author{
L. H. Keser - M. Fischer \\ Institute of Plant Sciences, University of Bern, Altenbergrain 21, \\ 3013 Bern, Switzerland \\ L. H. Keser $(\varangle) \cdot$ W. Dawson · M. van Kleunen \\ Ecology, Department of Biology, University of Konstanz, \\ Universitätsstraße 10, 78457 Constance, Germany \\ e-mail: lidewij.keser@gmail.com \\ Y.-B. Song $\cdot$ M. Dong \\ State Key Laboratory of Vegetation and Environmental \\ Change, Institute of Botany, Chinese Academy of Sciences, \\ Beijing 100093, China \\ F.-H. Yu \\ School of Nature Conservation, Beijing Forestry University, \\ Beijing 100083, China
}

non-invasive species showed significant foraging responses to heterogeneity in clonal growth organ biomass or in aboveground biomass of clonal offspring. Invasive species had, however, a greater positive foraging response in terms of root and belowground biomass than non-invasive species. Invasive species also produced more total biomass. Our results suggest that the ability for strong root foraging is among the characteristics promoting invasiveness in clonal plants.

Keywords Clonal growth · Nutrient heterogeneity · Nutrient foraging $\cdot$ Plant invasion $\cdot$ Pre-adaptation

\section{Introduction}

Clonal growth has been frequently mentioned as a trait that contributes to plant invasiveness (Reichard and Hamilton 1997; Lloret et al. 2005; Pyšek and Richardson 2007; Speek et al. 2011). Indeed, a considerable number of the most invasive plant species worldwide are capable of clonal growth (Pyšek 1997; Liu et al. 2006). The benefits clonal plant species may have over non-clonal species during invasion may include their ability to vegetatively reproduce and survive in the absence of suitable pollinators and the ability to effectively and quickly cover a site through clonal growth (Baker 1965; Pyšek 1997). Even though clonality is correlated with invasiveness, many clonal plant species have not become invasive, and it is not known which traits make some clonal species more invasive than others.

Phenotypic plasticity-the change in the expressed phenotype of a genotype as a function of the environment (Bradshaw 1965)—is frequently mentioned as a characteristic promoting invasiveness of plant species, both clonal and non-clonal (Baker 1965; Richards et al. 2006; Hulme 
2008). The idea here is that species capable of showing highly plastic responses to changes in certain environmental factors (hereafter referred to as "plastic species") can express optimal phenotypes in different habitats and under different growing conditions. Such plastic species should therefore be more likely pre-adapted to new environments encountered in the introduced regions. Although some studies have shown that highly invasive species were more plastic than native species (Drenovsky et al. 2008; Davidson et al. 2011) or less invasive alien species (Kercher and Zedler 2004; Dawson et al. 2011), this pattern was not found in several other studies (Schlaepfer et al. 2010; Palacio-López and Gianoli 2011; van Kleunen et al. 2011). Therefore, more research is needed to test to what extent plasticity in general promotes invasiveness, and for which specific plant traits and environmental factors in particular.

As many resources, such as nutrients, are generally patchily distributed at scales as small as a few centimeters (Hodge 2004 and references therein), different parts of a single plant may be exposed to different environmental conditions. Because individuals of many clonal plants can cover large areas as a consequence of their spreading growth form, they are especially likely to experience nutrient heterogeneity within the reach of their root systems. They can potentially adjust the morphology of their clonal growth organs (e.g., rhizomes and stolons) and roots (De Kroon and Hutchings 1995) in response to nutrient-rich and nutrient-poor patches. This so-called foraging response is thought to enable plants to better use the nutrients available to them. As a result, foraging could contribute to the success of clonal plant species (Jackson and Caldwell 1989), and might make clonal plant species with strong foraging responses more invasive than others. James et al. (2009) compared the nutrient foraging response of three invasive to that of three native forb species. They found no differences in the foraging response (log response ratio of root length density in high-nutrient and low-nutrient patches) between the invasive and native species. This type of comparison does not reveal why some alien species become invasive and others do not, and whether species are preadapted to become invasive (van Kleunen et al. 2010). So far, no direct comparison between the strength of the foraging responses of alien species of different invasion success has been made.

To test whether a strong foraging ability pre-adapts clonal species to become invasive, we conducted a multispecies greenhouse experiment in which we compared the nutrient-foraging response of native European clonal plant species differing in invasion success in the USA. We used six confamilial species pairs from six different plant families. Within each species pair, one species has become invasive (i.e., is a noxious weed and a natural-area invader) in the USA, and the other species has become naturalized but is not listed as invasive. We grew all 12 species in homogeneous and heterogeneous nutrient environments, and assessed their foraging responses (biomass of clonal growth organs and roots) and plant performance (total biomass production). We addressed the following questions:

1. Do European clonal plant species that have become invasive in the USA have a stronger foraging response to nutrient heterogeneity, i.e., have a higher ability to place relatively more root and/or clonal growth organ biomass in nutrient-rich than in nutrient-poor patches, than European clonal plant species that have not become invasive in the USA?

2. Is there a difference in overall performance under heterogeneous and under homogeneous nutrient conditions between European clonal plant species that have become invasive in the USA and species that have not become invasive?

\section{Materials and methods}

Species selection and pre-cultivation

We used 12 clonal plant species native to Europe, subdivided into six confamilial species pairs (Table 1). All species have been introduced to the USA and have become naturalized there to different degrees. Within each pair, the invasive species is listed as a noxious weed (http:// plants.usda.gov, visited June 2009) and as a natural-area invader (http://www.invasiveplantatlas.org, visited June 2009) in the USA, and the non-invasive species is not. Within each pair, the invasive species is also naturalized in more US states and Canadian provinces and territories, and has more references in the Global Compendium of Weeds (Randall 2002) than the non-invasive species (Table 1).

Before introduced alien species become invasive, they frequently experience a lag phase [i.e., they are present, but not spreading (Kowarik 1995; Larkin 2012)]. Therefore, our non-invasive species may not be invasive yet, simply because they might have been introduced more recently than our invasive species. The exact years of introduction of our species to North America are not known, because our species were most likely introduced by accident. Therefore, we looked for the earliest records of our species in online herbaria from all over North America. We found dated records for ten of the 12 species, and the earliest records of these species went back more than 100 years (Online Appendix; Table 1). For three species pairs, the record of the invasive species was older, and for one pair, the pattern was reversed. The remaining species with herbarium records belonged to different pairs. The overall trend towards older records for invasive species 
Table 1 The invasive $(I)$ and non-invasive $(N I)$ confamilial study species native to Europe, their Ellenberg nutrient-indicator values, invasiveness status, presence in the USA, occurrence in the Global Compendium of Weeds (GCW; Randall 2002) and type of clonal growth organs

\begin{tabular}{|c|c|c|c|c|c|c|c|}
\hline Plant family & Species & Ellenberg value $^{\mathrm{a}}$ & $\begin{array}{l}\text { Noxious weeds } \\
\text { (no. states) }^{\mathrm{b}}\end{array}$ & $\begin{array}{l}\text { Natural area } \\
\text { invader } \\
\text { (no. states and } \\
\text { counties) }\end{array}$ & $\begin{array}{l}\text { Presence in US } \\
\text { and Canada } \\
\text { (no. states) }^{\mathrm{b}}\end{array}$ & $\begin{array}{l}\text { Number of } \\
\text { records in } \\
\text { GCW }^{\mathrm{d}}\end{array}$ & $\begin{array}{l}\text { Clonal growth } \\
\operatorname{organ}(\mathrm{s})^{\mathrm{e}}\end{array}$ \\
\hline \multirow[t]{2}{*}{ Asteraceae } & $\begin{array}{l}\text { Sonchus arvensis } \\
\text { (I) }\end{array}$ & $X(X)$ & 14 & $1(154)$ & 55 & $44(21)$ & Rhizome \\
\hline & Inula salicina $(\mathrm{NI})$ & $3(2)$ & 0 & $0(0)$ & 3 & $1(0)$ & Rhizome \\
\hline \multirow[t]{2}{*}{ Apiaceae } & $\begin{array}{l}\text { Aegopodium } \\
\text { podagraria (I) }\end{array}$ & $8(8)$ & 3 & $6(152)$ & 37 & $23(13)$ & Rhizome \\
\hline & $\begin{array}{l}\text { Peucedanum } \\
\text { ostruthium (NI) }\end{array}$ & $7(7)$ & 0 & $0(0)$ & 7 & $2(1)$ & Rhizome \\
\hline \multirow[t]{2}{*}{ Poaceae } & Poa compressa (I) & $3(2)$ & 1 & $11(1,202)$ & 63 & $23(12)$ & Rhizome \\
\hline & Briza media $(\mathrm{NI})$ & $2(2)$ & 0 & $0(0)$ & 17 & $9(7)$ & Rhizome \\
\hline \multirow[t]{2}{*}{$\begin{array}{l}\text { Scrophulari- } \\
\text { aceae }\end{array}$} & $\begin{array}{l}\text { Linaria vulgaris } \\
\text { (I) }\end{array}$ & $5(3)$ & 8 & $12(1,076)$ & 62 & $46(21)$ & $\begin{array}{l}\text { Rhizome, root } \\
\text { with adventi- } \\
\text { tious buds }\end{array}$ \\
\hline & $\begin{array}{l}\text { Veronica chamae- } \\
\text { drys }(\mathrm{NI})\end{array}$ & $6(X)$ & 0 & $0(0)$ & 34 & $12(8)$ & Stolon, rhizome \\
\hline \multirow[t]{2}{*}{ Lamiaceae } & $\begin{array}{l}\text { Glechoma hedera- } \\
\text { cea (I) }\end{array}$ & 7 (7) & 1 & $13(1,117)$ & 58 & $36(14)$ & Stolon \\
\hline & $\begin{array}{l}\text { Teucrium scoro- } \\
\quad \text { donia }\end{array}$ & $3(3)$ & 0 & $0(0)$ & 4 & $7(6)$ & Rhizome \\
\hline \multirow[t]{2}{*}{$\begin{array}{l}\text { Caryophyl- } \\
\text { laceae }\end{array}$} & $\begin{array}{l}\text { Saponaria offici- } \\
\text { nalis (I) }\end{array}$ & $5(5)$ & 1 & $8(1,243)$ & 59 & $33(18)$ & Rhizome \\
\hline & Silene dioica $(\mathrm{NI})$ & $8(8)$ & 0 & $0(0)$ & 32 & $13(10)$ & $\begin{array}{l}\text { Rhizome, root } \\
\text { splitter, root } \\
\text { with adventi- } \\
\text { tious buds }\end{array}$ \\
\hline
\end{tabular}

\footnotetext{
${ }^{a}$ Ellenberg nutrient indicator value from http://statedv.boku.ac.at/zeigerwerte/, visited June 2009 and from Ellenberg et al. (1992) (between parentheses): values range from 1 (very low nutrient level) to 9 (high nutrient level) or species can grow under both nutrient-poor as well as nutrient-rich conditions $(X)$

${ }^{\mathrm{b}}$ http://plants.usda.gov, visited June 2009

${ }^{\mathrm{c}}$ http://www.invasiveplantatlas.org, visited June 2009. Number of states and between parentheses number of counties in which a species is considered a natural-area invader

${ }^{\mathrm{d}}$ Randall (2002). Number of references without the European references (native range) and between parentheses the number of references without the European and without the North-American references

e http://www.butbn.cas.cz/clopla/, visited May 2009
}

could reflect that they were introduced earlier than the noninvasive species. However, we think it more likely that the age of the record reflects a species' invasiveness, because invasive species are more likely to be encountered and collected by botanists, even when they were introduced at the same time as the non-invasive species (Bucharova and van Kleunen 2009; Daehler 2009). Furthermore, it is unlikely that there has been a bias towards earlier introduction of species with a strong foraging response. So even if invasive species were introduced earlier, a difference in foraging between invasive and non-invasive aliens would still be interesting and relevant.

We selected species pairs from the following plant families: Apiaceae, Asteraceae, Caryophyllaceae, Lamiaceae, Poaceae and Scrophulariaceae. Ten of our species grow clonally by producing rhizomes (i.e., belowground stems; Table 1). One invasive species (Glechoma hederacea) and one non-invasive species (Veronica chamaedrys) grow clonally by producing stolons (i.e., aboveground stems; Table 1) (Klimešová and Klimeš 2006). We used confamilial species pairs, which allowed us to avoid taxonomic bias of invasive and non-invasive species. The use of congeneric species pairs was not possible because of the strong restrictions placed on the species characteristics. In spring and summer 2009, we collected ramets of each study species from wild populations in Europe, i.e., the native range. To have a more representative sample per species, we used material from two populations instead of one population per species. These populations were at least $80 \mathrm{~km}$ apart. Within each population, we collected 20 ramets with a 
minimum inter-ramet distance of $5 \mathrm{~m}$ to reduce the chance of collecting multiple ramets from the same clone (i.e., genotype). We planted the collected ramets in containers $(60 \times 17.5 \times 15 \mathrm{~cm})$ filled with a 1:1 mixture of sand and peat soil, and placed them in an uncontrolled greenhouse in Muri near Bern, Switzerland (46.55.1631N, 7.30.0853E). Plants were watered regularly, and left to grow and clonally propagate until the start of the experiment in early June 2010.

\section{Experimental set-up}

We carried out the experiment in the same uncontrolled greenhouse, where the pre-cultivation took place. To allow plants to produce offspring ramets at a natural distance and depth, we used large, circular pots $(60 \mathrm{~cm}$ diameter, $36 \mathrm{~cm}$ high) filled with $60 \mathrm{~L}$ of a 1:1 mixture of sieved sand $(0-4 \mathrm{~mm})$ and Swiss agricultural soil with high clay content. The background $\mathrm{N}$ concentration in our pots was quite high (total soil $\mathrm{N}$ concentration was 0.24 mass percent). One may expect species with a high demand for nutrients to forage more under these circumstances than species with a low nutrient demand. For this reason, we balanced the nutrient needs (i.e., Ellenberg nutrient indicator values) of the invasive and non-invasive species across species pairs (Table 1). Therefore, it is unlikely that nutrient demand per se influenced the difference in the foraging responses between invasive and non-invasive species in our experiment.

Half of the pots were assigned to a homogeneous nutrient treatment, the other half to a heterogeneous nutrient treatment. Each pot received $135 \mathrm{~g}$ slow-release fertilizer (Osmocote Exact Standard 5-6M). In the pots assigned to the homogeneous treatment, we mixed all fertilizer homogeneously into the soil. In the pots assigned to the heterogeneous treatment, all fertilizer was added to the two quarters directed to the north and the south (Fig. 1). We prevented nutrient leakage between the four pot quarters by taping four pieces of water-impermeable root-barrier (RootBarrier 325; RootBarrier, Lelystad, the Netherlands) to the side and bottom of all 288 pots before they were filled with soil. We left a $10 \times 10-\mathrm{cm}$ section in the center of each pot root-barrier-free to allow development of roots and clonal growth organs in any direction (Fig. 1).

From each of the two populations per species, we planted offspring ramets of six plants in the experiment. From each of these 12 plants per species, we took two daughter ramets of similar size (i.e., 24 ramets per species). We cut rhizomes or stolons that we took from the same plant into pieces of equal size (and all $<14 \mathrm{~cm}$ ), and removed all flowers, if any. Although Silene dioica had produced rhizomes in the field, it had not developed them
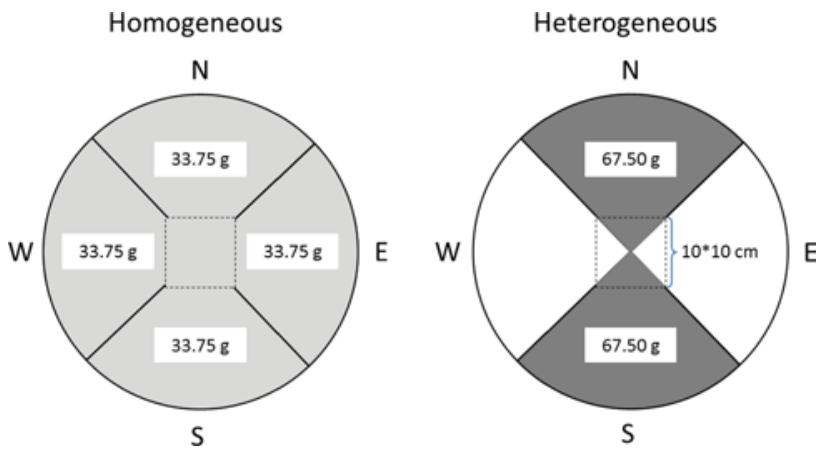

Fig. 1 Illustration of experimental treatments. Pots were divided into four quarters [north $(\mathrm{N})$, east $(\mathrm{E})$, south $(\mathrm{S})$, west $(\mathrm{W})$ ], which were separated from each other by water-impermeable root barrier, leaving a $10 \times 10-\mathrm{cm}$ root-barrier-free space in the middle. In the homogeneous nutrient treatment, all pot quarters were enriched with $33.75 \mathrm{~g}$ slow-release fertilizer. In the heterogeneous treatment, the $\mathrm{N}$ and $\mathrm{S}$ quarters were enriched with a double dose of fertilizer; the $\mathrm{E}$ and $\mathrm{W}$ quarters did not receive any additional fertilizer. The total amount of fertilizer was thus the same for both treatments

during pre-cultivation. Therefore, we cut two similarly sized rosettes from each mother ramet. We then randomly assigned one of the two daughter ramets of each plant to the heterogeneous nutrient treatment and the other ramet to the homogeneous nutrient treatment, so that the same genetic material was represented in each treatment. We planted ramets in the middle of the pots on 6 June 2010 . To avoid pre-determination of growth direction of clonal growth organs into the quarters, we placed rhizomes and stolons in line with the root barrier. We placed the 288 pots in the glasshouse in a randomized block design with six blocks. Each block contained the two ramets from one plant from each population. As a measure of initial size, we counted the number of leaves on each plant.

\section{Harvest and measurements}

From 1 to 26 October 2010 (i.e., 4 months after the start of the experiment), we harvested biomass from each pot in five parts: the central $10 \times 10-\mathrm{cm}$ section and the four surrounding pot quarters (Fig. 1). First, we cut aboveground biomass at soil level. For the two stoloniferous species $V$. chamaedrys and $G$. hederacea, we separated stolons from other aboveground parts. Stolons of $G$. hederacea had grown out of their pots, and we therefore separated aboveground biomass into "inside-" and "outside"-pot biomass. We washed belowground parts from the soil, and separated rhizomes from the roots. Linaria vulgaris only developed roots with adventitious buds but no true rhizomes. All biomass samples were dried at $80{ }^{\circ} \mathrm{C}$ for at least $72 \mathrm{~h}$ and weighed. Ten plants died during the experiment, and were excluded from the analyses. 


\section{Statistical analyses}

We performed two sets of analyses. First, we tested whether there was a difference in foraging response between invasive and non-invasive plant species. For these analyses, we compared clonal growth organ biomass, belowground biomass (including rhizomes), root biomass and aboveground biomass (including stolons) in the different pot quarters. Because we were interested in whether plants can differentiate between low and high nutrient levels rather than between each of the four pot quarters, we combined data of the east and west pot quarters (corresponding to low nutrient patches in the heterogeneous treatment) and of the north and south pot quarters (corresponding to high nutrient patches in the heterogeneous treatment). The central $10 \times 10 \mathrm{~cm}$ was not included in these analyses. This meant that we had two values per pot in these analyses. Second, we tested whether there was a difference in plant performance between invasive and non-invasive plant species growing in a homogeneous or a heterogeneous nutrient environment. For this analysis, total biomass of all five pot fractions was combined (i.e., there was one value per pot).

We analyzed the data with linear mixed models (Pinheiro et al. 2010) using the function lme in the statistical program R (R Development Core Team 2010). These models allowed us to take the nested design of our experiment into account (included as a random structure), and are relatively robust when data are not completely balanced. We also used the lme function because this, in contrast to other mixed-model functions in $\mathrm{R}$, allowed us to correct for the large differences in variance between species (i.e., heteroscedasticity) by adding species variances as a weighting factor (Zuur et al. 2009).

Invasiveness of species, the nutrient treatment (homogeneous versus heterogeneous treatment), the patch direction (north + south vs. east + west) and their interactions were included as fixed terms. To account for variation in initial size, the number of leaves at the start of the experiment was included as a covariable. We accounted for the hierarchical design of our study by including a nested random structure into the models: family/species/population/plant/ pot. Because the lme function in R only allows for one random structure at a time, block was included as a cofactor in the fixed part of the model. When total biomass of each plant in a pot was analyzed, growth direction was excluded from the fixed terms, and pot was excluded from the random structure.

We tested the significance of the three-way interactions by removing each three-way interaction in turn and comparing these models to the full model. We tested the significance of the two-way interactions by removing each one in turn and comparing these models to the model with all two-way interactions. We tested the significance of the single explanatory variables by removing each one in turn and comparing these models to a model with all explanatory variables in it, but none of their interactions. To achieve normality of the residuals, we square-root transformed all data for performance of the whole clone, and we did the same for the following analyses of foraging response: aboveground biomass and belowground biomass. We fourth-root transformed root biomass and clonal growth organ biomass (Table 2). Plants that did not produce clonal growth organs were excluded from the analyses in which we tested foraging effects in clonal growth organs or aboveground biomass. This was particularly the case in $S$. dioica, which hardly showed any clonal growth. This species was therefore excluded from the analysis of clonal growth organs. Because L. vulgaris clonally reproduced through roots with adventitious buds, rather than through rhizomes, the species was excluded from the analysis of clonal growth organs.

\section{Results}

Foraging response

\section{Clonal growth organs}

The biomass of clonal growth organs did not differ between the homogeneous and heterogeneous nutrient treatments (Table 2; Fig. 2). Overall, invasive plant species achieved a greater biomass of clonal growth organs than non-invasive plant species (Table 2; Fig. 2). However, invasive and noninvasive plants did not differ in their responses of biomass of clonal growth organs to the nutrient treatment and the direction of the pot parts (Table 2; Fig. 2, Online Appendix; Fig. 1a).

\section{Belowground biomass}

There was no difference in overall root and belowground biomass between the homogeneous and the heterogeneous nutrient treatment (Table 2; Fig. 2). However, under heterogeneous, but not under homogeneous nutrient conditions, plants produced, on average, more root and belowground biomass in the north-south direction (i.e., the high-nutrient pot parts of the heterogeneous treatment) than in the eastwest direction (Table 2; Fig. 2). This indicates that there was a foraging response.

Invasive species produced more root and belowground biomass than non-invasive species (Table 2; Fig. 2). For invasive species, plants produced similar root biomass and belowground biomass in the north-south and the east-west direction in the homogeneous treatment, but produced more in the north-south than in the east-west direction in the 


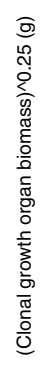

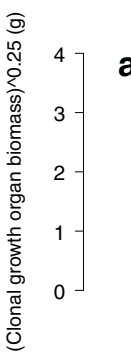

a

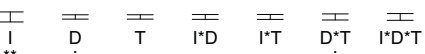
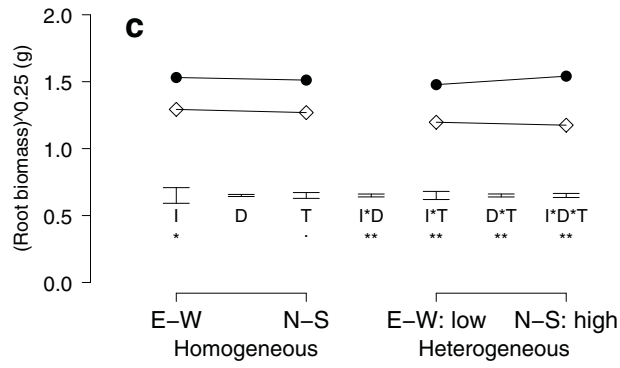

Fig. 2 Modeled mean a clonal growth organ biomass, b root biomass, $\mathbf{c}$ belowground biomass, and $\mathbf{d}$ aboveground biomass of invasive (black circles) and non-invasive (white diamonds) clonal plant species in two pot parts: $\mathrm{E}-\mathrm{W}$ and $\mathrm{N}-\mathrm{S}$. In the homogeneous treatment, all four pot quarters received an equal amount of nutrients. In the heterogeneous treatment, all nutrients were added to the $\mathrm{N}$ and
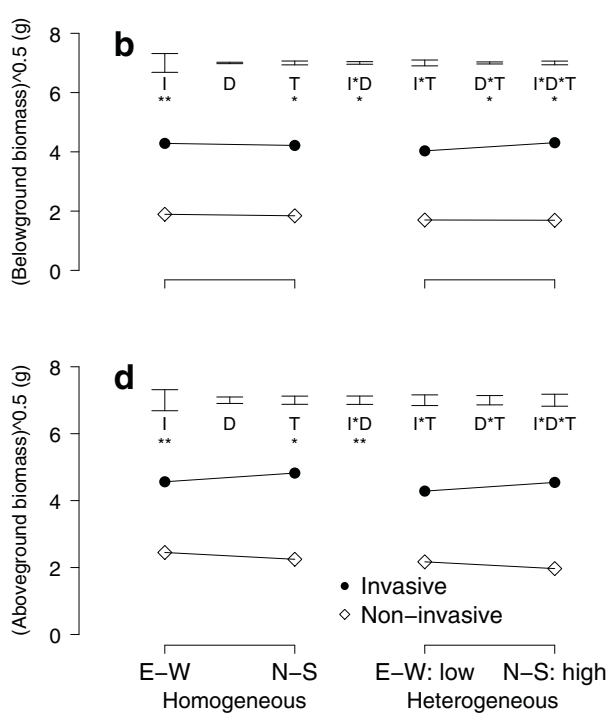

$\mathrm{S}$ quarters of the pot (high), whereas the $\mathrm{E}$ and $\mathrm{W}$ quarters did not receive any extra nutrients (low). Error bars indicate the modeled SEs for the effects of pot quarter $(D)$, treatment $(T)$, invasiveness $(I)$ and the interactions between these explanatory variables $\left(I^{*} D, I^{*} T, D^{*} T\right.$, $\left.I^{*} D^{*} T\right) .0 .05>p<0.1, * 0.01>p<0.05, * * 0.001>p<0.01$
Table 2 Results of fixed terms in linear mixed models for the nutrient foraging response, expressed in clonal growth organ (CGO), belowground, root and aboveground biomass; and plant performance, expressed in aboveground, belowground and total plant biomass, of invasive and non-invasive plant species

\begin{tabular}{|c|c|c|c|c|c|c|c|c|c|c|}
\hline Response variable & Transformation & Block & Start size & $I$ & $T$ & $D$ & $I \times T$ & $I \times D$ & $T \times D$ & $I \times T \times D$ \\
\hline \multicolumn{11}{|l|}{ Foraging $^{\mathrm{a}}$} \\
\hline CGO biomass & ${ }^{\wedge} 0.25$ & $\begin{array}{l}15.59 \\
(0.008)\end{array}$ & $\begin{array}{l}0.72 \\
(0.395)\end{array}$ & $\begin{array}{l}7.53 \\
(0.006)\end{array}$ & $\begin{array}{l}1.61 \\
(0.204)\end{array}$ & $\begin{array}{l}3.09 \\
(0.079)\end{array}$ & $\begin{array}{l}0.35 \\
(0.553)\end{array}$ & $\begin{array}{l}0.72 \\
(0.393)\end{array}$ & $\begin{array}{l}3.54 \\
(0.058)\end{array}$ & $\begin{array}{l}0.02 \\
(0.877)\end{array}$ \\
\hline Belowground biomass & ${ }^{\wedge} 0.5$ & $\begin{array}{l}18.96 \\
(0.002)\end{array}$ & $\begin{array}{l}12.43 \\
(<0.000)\end{array}$ & $\begin{array}{l}9.68 \\
(0.002)\end{array}$ & $\begin{array}{l}1.53 \\
(0.217)\end{array}$ & $\begin{array}{l}0.08 \\
(0.781)\end{array}$ & $\begin{array}{l}0.23 \\
(0.632)\end{array}$ & $\begin{array}{l}4.05 \\
(0.044)\end{array}$ & $\begin{array}{l}4.78 \\
(0.029)\end{array}$ & $\begin{array}{l}5.78 \\
(0.016)\end{array}$ \\
\hline Root biomass & $\wedge 0.25$ & $\begin{array}{l}9.737228 \\
(0.083)\end{array}$ & $\begin{array}{l}8.917511 \\
(0.003)\end{array}$ & $\begin{array}{l}4.37 \\
(0.037)\end{array}$ & $\begin{array}{l}3.13 \\
(0.077)\end{array}$ & $\begin{array}{l}0.03 \\
(0.857)\end{array}$ & $\begin{array}{l}13.01 \\
(0.005)\end{array}$ & $\begin{array}{l}6.97 \\
(0.008)\end{array}$ & $\begin{array}{l}7.92 \\
(0.005)\end{array}$ & $\begin{array}{l}6.86 \\
(0.009)\end{array}$ \\
\hline Aboveground biomass & $\wedge^{\wedge} 0.5$ & $\begin{array}{l}9.42 \\
(0.094)\end{array}$ & $\begin{array}{l}2.75 \\
(0.097)\end{array}$ & $\begin{array}{l}7.43 \\
(0.006)\end{array}$ & $\begin{array}{l}4.27 \\
(0.039)\end{array}$ & $\begin{array}{l}0.55 \\
(0.457)\end{array}$ & $\begin{array}{l}0.63 \\
(0.429)\end{array}$ & $\begin{array}{l}6.83 \\
(0.009)\end{array}$ & $\begin{array}{l}1.12 \\
(0.289)\end{array}$ & $\begin{array}{l}0.15 \\
(0.704)\end{array}$ \\
\hline \multicolumn{11}{|l|}{ Plant performance ${ }^{\mathrm{b}}$} \\
\hline Total biomass & $\wedge^{\wedge} 0.5$ & $\begin{array}{l}16.56 \\
(0.005)\end{array}$ & $\begin{array}{l}2.39 \\
(0.123)\end{array}$ & $\begin{array}{l}8.11 \\
(0.004)\end{array}$ & $\begin{array}{l}9.99 \\
(0.002)\end{array}$ & & $\begin{array}{l}0.00 \\
(0.989)\end{array}$ & & & \\
\hline Total aboveground biomass & $\wedge 0.5$ & $\begin{array}{l}17.46 \\
(0.004)\end{array}$ & $\begin{array}{l}1.72 \\
(0.190)\end{array}$ & $\begin{array}{l}5.14 \\
(0.023)\end{array}$ & $\begin{array}{l}9.88 \\
(0.002)\end{array}$ & & $\begin{array}{l}0.00 \\
(0.960)\end{array}$ & & & \\
\hline Total belowground biomass & $\wedge 0.5$ & $\begin{array}{l}11.02 \\
(0.051 \dagger)\end{array}$ & $\begin{array}{l}2.15 \\
(0.143)\end{array}$ & $\begin{array}{l}8.10 \\
(0.004)\end{array}$ & $\begin{array}{l}9.42 \\
(0.002)\end{array}$ & & $\begin{array}{l}0.05 \\
(0.827)\end{array}$ & & & \\
\hline
\end{tabular}

Presented are the log likelihood ratios and corresponding $p$-values in parentheses $(P<0.05$ in italics $)$ for fixed terms of model comparisons in which a model with the explanatory variable was compared to a model without the explanatory variable using the model selection method as described in the Materials and methods section

$I$ Invasiveness, $T$ treatment (homogeneous or heterogeneous), $D$ direction (north-south vs. east-west)

a Models contained the following nested random structure: family/species/population/plant/pot

b Models contained the following nested random structure: family/species/population/plant 
heterogeneous treatment (Table 2; Fig. 2). For non-invasive species, however, there were no differences in root biomass and belowground biomass between the homogeneous and the heterogeneous treatments (Table 2; Fig. 2). Such differences in the effects of nutrient treatments on the belowground biomass placement between invasive and non-invasive species were reflected in a significant invasiveness $\mathrm{x}$ treatment $\mathrm{x}$ direction interaction (Table 2). These results indicate that, on average, invasive species had a stronger belowground foraging response than non-invasive plant species [Table 2; Fig. 2, Online Appendix (Fig. 1b, c)].

\section{Aboveground biomass}

Plants produced more aboveground biomass in the homogeneous than in the heterogeneous nutrient treatment (Table 2; Fig. 2). Independent of nutrient treatment, invasive plants produced more aboveground biomass in the north-south direction than in the east-west direction, whereas non-invasive plants showed a slight trend for the opposite pattern (Table 2; Fig. 2). The biomass response to the homogeneous and heterogeneous treatment was not different for invasive and non-invasive species. Furthermore, there were no significant foraging responses in terms of aboveground-biomass production between invasive and non-invasive species [i.e., no significant invasiveness $\times$ treatment $\times$ direction interaction, Table 2; Fig. 2, Online Appendix (Fig. 1d)].

\section{Overall plant performance}

On average, plants growing in the homogeneous treatment produced more biomass than plants in the heterogeneous treatment (Table 2; Fig. 3), and invasive species produced more biomass than non-invasive species [Table 2; Fig. 3, Online Appendix (Fig. 2)]. These two effects were also significant for total aboveground biomass (Table 2) and total belowground biomass (Table 2).

\section{Discussion}

We found that invasive clonal plant species in our experiment had a significantly higher belowground foraging response than non-invasive ones. This difference that was most striking in the Asteraceae species pair. We found more root biomass as well as more belowground biomass (including mass of roots and rhizomes) in nutrient-enriched patches compared to nutrient-poor patches across our invasive species. Because foraging is most likely an expression of adaptive phenotypic plasticity, our study supports the idea that the potential for strong phenotypic plasticity plays a role in plant invasions (Baker 1965; Richards et al.

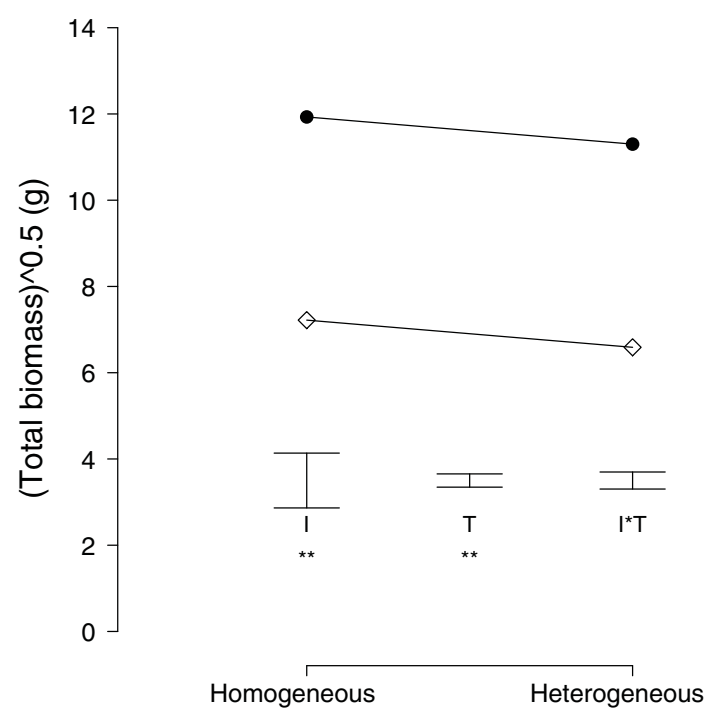

Fig. 3 Modeled mean total biomass of invasive (black circles) and non-invasive (white diamonds) clonal plant species in homogeneous and heterogeneous nutrient environments. Error bars indicate the modeled SEs for the effects of $T, I$ and $I^{*} T$. $* * 0.001>p<0.01$

2006; Hulme 2008). Furthermore, a growing body of recent multi-species research shows that invasiveness of plant species is partly determined by the way they deal with or respond to soil nutrient availability (Dostál et al. 2013) or changes therein (Burns 2008; Dawson et al. 2012a, b). We can now add to this list that the way they deal with smallscale spatial heterogeneity in the distribution of soil nutrients may play a role in species invasiveness as well.

There could be several roles of clonal growth organs in foraging of clonal plants. First, clonal plants themselves could actively grow more ramets into high-nutrient patches. Second, placement of ramets could be undirected and when these ramets encounter a nutrient-rich patch, an increase in root proliferation or nutrient-uptake rate ensures exploitation of nutrients in that patch (De Kroon and Hutchings 1995). In our experiment, we provided the ramets with large pots, because we wanted to give all 12 species enough space to clonally reproduce in a natural way and give them the opportunity to forage in either manner described. Even though most plants produced a considerable number of ramets, we did not observe more clonal growth organ biomass in nutrient-rich patches than in nutrient-poor patches in either invasive or non-invasive species. Part of this lack in response could have been caused by the relatively high background nutrient concentration of the soil. If the background nutrient concentration would have been lower, the response might have been stronger. In any case, the observed increase in root- and belowground biomass in nutrient-rich patches suggests that the second mechanism of foraging was taking place. These results are in line with the ideas of de Kroon and Hutchings (1995), who 
suggested that clonal plants forage for soil nutrients via morphological plasticity of orthotropic roots, rather than through directed ramet placement, as the latter was seldom found in previous studies. Moreover, Stuefer (1996) argued that clonal foraging through directed ramet placement may be limited due to the unpredictability of natural nutrient patches in space and time.

Our results suggest that some clonal plants may be partly pre-adapted to become invasive elsewhere through a strong root foraging response to stable nutrient patches. This belowground foraging response was, however, not reflected in the allocation of aboveground biomass between the patches. Interestingly, irrespective of the nutrient treatment, invasive species produced more aboveground biomass in the north-south than in the east-west direction, whereas non-invasive species showed a slight trend for the opposite pattern. Possibly, this unexpected finding indicates that invasive and non-invasive plants differ in their strategy of optimizing light interception. We therefore suggest that future studies should test whether invasive and non-invasive plant species differ in their ability to forage for light.

The strength of the foraging response has been found to be correlated with species characteristics typical for weedy species such as a fast relative growth rate and a fast resource uptake in a database study by Kembel et al. (2008). We found that the response was stronger in invasive species than in non-invasive species. As also found in several other comparative studies (e.g., Schlaepfer et al. 2010; Van Kleunen et al. (2011), our invasive species produced more biomass - indicating a higher relative growth ratethan our non-invasive species. Our results thus corroborate the results of Kembel et al. (2008), but this also means that the stronger foraging responses in invasive species could also be explained by their probably higher relative growth rate.

Plants do not only respond to heterogeneity by morphological plasticity, but can also regulate their nutrient-uptake kinetics (Fransen et al. 1999; James et al. 2009) by increasing the activity of nutrient transporters in the root cells (Bassirirad 2000). This physiological foraging response is expected to be stronger in species with a low relative growth rate or when nutrient pulses are short (Robinson and Van Vuuren 1998; James et al. 2009). Since most of our non-invasive species did not grow as fast as the invasive species, this may also explain why we did not find a significant foraging response in the non-invasive species. Furthermore, it could also explain why we found no difference in the total biomass response to nutrient heterogeneity between the invasive and the non-invasive species.

In our experiment, when growing by themselves in competition-free pots, invasive species showed a stronger foraging response than the non-invasive species (Table 2; Fig. 2). In nature, plants usually grow in competition with others and this can interact with the way they forage. Foraging has been reported to increase the competitive potential of species by enabling them to increase their nutrient uptake rate in nutrient-rich patches (Robinson et al. 1999), and this effect has been hypothesized to be additive for competitive species and less so for competitively weaker species (Mommer et al. 2012). It has also been shown that the proportion of competitive and competitive-ruderal strategists among established alien plant species in the Czech Republic is much higher than in the native flora (Pyšek et al. 1995). Therefore, we would expect invasive species to be able to forage more for nutrients in competitive environments than non-invasive species. This, however, remains to be tested.

The root-foraging responses we found in our experiment are responses to long-term stable patches of increased nutrient availability. In natural soils, nutrient availability is frequently not only spatially variable, but also temporally variable (Stuefer 1996; James et al. 2009). In many systems, nutrients generally become available in pulses through breakdown of organic material. Such fluctuating resource levels could increase invasibility of native ecosystems (Davis et al. 2000). Fast and effective exploitation of such pulses could be advantageous to species growing in competition with others and as such, one might expect invasive species to be better in this respect than non-invasive species (Dawson et al. 2012a; Parepa et al. 2013). In comparison to co-occurring native species, the $\mathrm{N}$ uptake rate was 15 times larger in invasive than in native forbs in a foraging experiment in which all plants were supplied with weekly nutrient pulses (James et al. 2009). It would be very interesting to know whether this is the case for non-invasive alien species too.

To our knowledge, our experiment is the first to compare the nutrient foraging response of invasive to that of noninvasive clonal plant species. We did not find a significant foraging response by means of plasticity in clonal growth organs. However, we found slightly stronger root- and belowground-foraging responses to stable nutrient patches in invasive species compared to non-invasive species. Even though this difference in foraging response may be related to the differences in relative growth rate of the selected study species in this experiment, we believe that it still gives insight into one of the potential plant traits underlying species invasiveness. To find out whether this relationship between foraging response and invasiveness is a general one, more experiments with other species are needed, as well as experiments in which species pairs are corrected for relative growth rates. Furthermore, since we have only investigated biomass responses, it would also be very interesting to find out which morphological and/or physiological changes cause the difference in the observed biomass foraging response between invasive and non-invasive species. 
Acknowledgments We thank Andreas Ensslin, Anne Kempel, Arend-Jan Baakman, Babette Keser, Sebastian Keller, Bernadette van den Eeden, Christine Heiniger, Christophe Bornand, Corina Del Fabbro, Eelke Jongejans, Gemma Rutten, Hanneke van Lierop, Laura Keser, Madalin Parepa, Marc Vis, Martina Bisculm, Oana Burlacu, Peter Ellenberger, Pius Winniger, Roos Teijken, Sylvia Zingg, Thomas Chrobock, Vitek Latzel, Wim Jongejans, Yuan-Ye Zhang, Yvonne Zuercher and Zhengwen Wang for their practical help at various stages of the experiment. This project was funded by the Sino-Swiss Science and Technology Cooperation (project no. IZLCZ3 123973).

\section{References}

Baker HG (1965) Characteristics and modes of origin of weeds. The genetics of colonizing species. Academic Press, New York, pp $147-168$

Bassirirad H (2000) Kinetics of nutrient uptake by roots: responses to global change. New Phytol 147:155-169

Bradshaw A (1965) Evolutionary significance of phenotypic plasticity in plants. Adv Genet 13:115-155

Bucharova A, Van Kleunen M (2009) Introduction history and species characteristics partly explain naturalization success of North American woody species in Europe. J Ecol 97:230-238. doi:10.1111/j.1365-2745.2008.01469.x

Burns JH (2008) Demographic performance predicts invasiveness of species in the Commelinaceae under high-nutrient conditions. Ecol Appl 18:335-346

Daehler CC (2009) Short lag times for invasive tropical plants: evidence from experimental plantings in Hawai'i. PLoS ONE 4:e4462. doi:10.1371/journal.pone.0004462

Davidson AM, Jennions M, Nicotra AB (2011) Do invasive species show higher phenotypic plasticity than native species and, if so, is it adaptive? A meta-analysis. Ecol Lett 14:419-431. doi:10.1111/j.1461-0248.2011.01596.x

Davis MA, Grime JP, Thompson K (2000) Fluctuating resources in plant communities: a general theory of invasibility. J Ecol 88:528-534. doi:10.1046/j.1365-2745.2000.00473.x

Dawson W, Fischer M, Van Kleunen M (2011) The maximum relative growth rate of common UK plant species is positively associated with their global invasiveness. Glob Ecol Biogeogr 20:299-306. doi:10.1111/j.1466-8238.2010.00599.x

Dawson W, Fischer M, Van Kleunen M (2012a) Common and rare plant species respond differently to fertilisation and competition, whether they are alien or native. Ecol Lett 15:873-880. doi:10.1111/j.1461-0248.2012.01811.x

Dawson W, Van Kleunen M, Rohr R, Fischer M (2012b) Alien plant species with a wider global distribution are better able to capitalize on increased resource availability. New Phytol 194:859-867

De Kroon H, Hutchings MJ (1995) Morphological plasticity in clonal plants: the foraging concept reconsidered. J Ecol 83:143-152

Dostál P, Dawson W, Van Kleunen M et al (2013) Central European plant species from more productive habitats and with wider productivity niches are more invasive at a global scale. Glob Ecol Biogeogr 22:64-72. doi:10.1111/j.1466-8238.2011.00754.x

Drenovsky RE, Martin CE, Falasco MR, James JJ (2008) Variation in resource acquisition and utilization traits between native and invasive perennial forbs. Am J Bot 95:681-687. doi:10.3732/ ajb. 2007408

Ellenberg H, Weber HE, Dull R et al (1992) Zeigerwerte von Pflanzen in Mitteleuropa. Scr Geobot 18:1-248

Fransen B, Blijjenberg J, De Kroon H (1999) Root morphological and physiological plasticity of perennial grass species and the exploitation of spatial and temporal heterogeneous nutrient patches. Plant Soil 211:179-189
Hodge A (2004) The plastic plant: root responses to heterogeneous supplies of nutrients. New Phytol 162:9-24. doi:10.1111/j.1469-8137.2004.01015.x

Hulme P (2008) Phenotypic plasticity and plant invasions: is it all Jack? Funct Ecol 22:3-7. doi:10.1111/j.1365-2435.2007.01369.x

Jackson R, Caldwell MM (1989) The timing and degree of root proliferation in fertile-soil microsites for three cold-desert perennials. Oecologia 81:149-153

James JJ, Mangold JM, Sheley RL, Svejcar T (2009) Root plasticity of native and invasive Great Basin species in response to soil nitrogen heterogeneity. Plant Ecol 202:211-220. doi:10.1007/ s11258-008-9457-3

Kembel SW, De Kroon H, Cahill JF Jr, Mommer L (2008) Improving the scale and precision of hypotheses to explain root foraging ability. Ann Bot 101:1295-1301. doi:10.1093/aob/men044

Kercher SM, Zedler JB (2004) Flood tolerance in wetland angiosperms: a comparison of invasive and noninvasive species. Aquat Bot 80:89-102. doi:10.1016/j.aquabot.2004.08.003

Klimešová J, Klimeš L (2006) CLO-PLA3: a database of clonal growth architecture of central-European plants. http://www.butbn.cas.cz/clopla

Kowarik I (1995) Time lags in biological invasions with regard to the success and failure of alien species. In: Pysek P, Prach K, Rejmanek M, Wade M (eds) Plant invasions-general aspects and special problems. SPB Academic, Amsterdam, pp 15-38

Larkin DJ (2012) Lengths and correlates of lag phases in upper-Midwest plant invasions. Biol Invasions 14:827-838. doi:10.1007/ s10530-011-0119-3

Liu J, Dong M, Miao SL et al (2006) Invasive alien plants in China: role of clonality and geographical origin. Biol Invasions 8:14611470. doi:10.1007/s10530-005-5838-x

Lloret F, Médail F, Brundu G et al (2005) Species attributes and invasion success by alien plants on Mediterranean islands. J Ecol 93:512-520. doi:10.1111/j.1365-2745.2005.00979.x

Mommer L, Van Ruijven J, Jansen C et al (2012) Interactive effects of nutrient heterogeneity and competition: implications for root foraging theory? Funct Ecol 26:66-73. doi:10.1111/j.1365-2435.2011.01916.x

Palacio-López K, Gianoli E (2011) Invasive plants do not display greater phenotypic plasticity than their native or noninvasive counterparts: a meta-analysis. Oikos 120:1393-1401. doi:10.1111/j.1600-0706.2010.19114.x

Parepa M, Fischer M, Bossdorf O (2013) Environmental variability promotes plant invasion. Nat Commun. doi:10.1038/ncomms2632

Pinheiro J, Bates D, DebRoy S et al (2010) nlme: linear and nonlinear mixed effects models

Pyšek P (1997) Clonality and plant invasions: can a trait make a difference. In: de Kroon H, Van Groenendael JM (eds) The ecology and evolution of clonal plants. Backhuys, Leiden, pp 405-427

Pyšek P, Richardson DM (2007) Traits associated with invasiveness in alien plants: where do we stand? In: Nentwig W (ed) Biological invasions. Springer, Berlin, pp 97-126

Pyšek P, Prach K, Smilauer P (1995) Relating invasion success to plant traits: an analysis of the czech alien flora. In: Pyšek P, Prach K, Rejmánek M, Wade MJ (eds) Plant invasions: general aspects and special problems. Academic Publishing, Amsterdam, pp $39-60$

$\mathrm{R}$ development core team (2010) R: a language and environment for statistical computing, reference index version 2.12.0. ISBN 3-900051-07-0

Randall R (2002) A global compendium of weeds. Richardson, Melbourne

Reichard SH, Hamilton CW (1997) Predicting invasions of woody plants introduced into North America. Conserv Biol 11:193-203

Richards CL, Bossdorf O, Muth NZ et al (2006) Jack of all trades, master of some? On the role of 
phenotypic plasticity in plant invasions. Ecol Lett 9:981-993. doi:10.1111/j.1461-0248.2006.00950.x

Robinson D, Van Vuuren M (1998) Responses of wild plants to nutrient patches in relation to growth rate and life-form. In: Lambers $\mathrm{H}$, Poorter H, van Vuuren $\mathrm{M}$ (eds) Inherent variation in plant growth. Physiological mechanisms and ecological consequences. Backhuys, Leiden, pp 237-257

Robinson D, Hodge A, Griffiths BS, Fitter AH (1999) Plant root proliferation in nitrogen-rich patches confers competitive advantage. Proc R Soc Lond B Biol Sci 266:431-435

Schlaepfer DR, Glättli M, Fischer M, Van Kleunen M (2010) A multispecies experiment in their native range indicates pre-adaptation of invasive alien plant species. New Phytol 185:1087-1099. doi:10.1111/j.1469-8137.2009.03114.x

Speek TAA, Lotz LAP, Ozinga WA et al (2011) Factors relating to regional and local success of exotic plant species in their new range. Divers Distrib 17:542-551. doi:10.1111/j.1472-4642.2011.00759.x

Stuefer JF (1996) Potential and limitations of current concepts regarding the response of clonal plants to environmental heterogeneity. Vegetatio 127:55-70. doi:10.1007/BF00054847

Van Kleunen M, Dawson W, Schlaepfer DR et al (2010) Are invaders different? A conceptual framework of comparative approaches for assessing determinants of invasiveness. Ecol Lett 13:947-958. doi:10.1111/j.1461-0248.2010.01503.x

Van Kleunen M, Schlaepfer DR, Glaettli M, Fischer M (2011) Preadapted for invasiveness: do species traits or their plastic response to shading differ between invasive and non-invasive plant species in their native range? J Biogeogr 38:1294-1304. doi:10.1111/j.1365-2699.2011.02495.x

Zuur AF, Ieno EN, Walker NJ et al (2009) Mixed effects models and extensions in ecology with R. Springer, New York 